\title{
A oposição aos pavilhões do parque Ibirapuera (1950-1954)
}

\begin{abstract}
Ana Cláudia Castilho Barone ${ }^{1}$
RESUMO: Este artigo trata das disputas em torno da realização do parque Ibirapuera, na primeira metade da década de 1950, quando a Prefeitura Municipal de São Paulo, com o apoio do Governo do Estado, decidiu implementá-lo, com o propósito de nele sediar as comemorações do seu $400^{\circ}$ aniversário de fundação. O Ibirapuera é considerado o primeiro parque metropolitano de São Paulo. Foi construído em 1954, momento em que a cidade

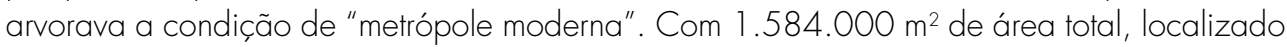
junto a bairros nobres, o parque foi equipado com um conjunto de edifícios desenhados por Oscar Niemeyer, destinados a abrigar exposições comemorativas. Sua construção ensejou uma série de manifestações de oposição, consolidadas em torno de um grupo que teve franca representação em diversos meios institucionais e de comunicação. Posteriormente, no entanto, essa oposição foi totalmente silenciada tanto pelos agentes sociais envolvidos no processo quanto pela bibliografia sobre o assunto. Procura-se, aqui, levantar as questões em torno de tal oposição, com vistas a estabelecer um contraponto ao caráter comemorativo da própria fundação da cidade, permitindo a superação do olhar celebratório e de elogio do progresso paulistano. Essa investigação delineia um campo de conflitos e disputas, indicando que, naquele momento, não havia continuidade entre a celebração do aniversário da cidade e a modernidade dos pavilhões do Ibirapuera, mas sim uma série de embates políticos de relevância para o urbanismo em São Paulo, que merecem ser recuperados.

PALAVRAS-CHAVE: Urbanismo paulistano. Criação do parque Ibirapuera. Oposição aos pavilhões do Ibirapuera. IV Centenário de São Paulo.

ABSTRACT: This article discusses the disagreements around the construction of Ibirapuera Park in the first half of the 1950s, when the municipal government of São Paulo decided, with support from the state government, to implement the project for the purpose of staging the celebrations of the city's 400 th anniversary on its premises. Ibirapuera is regarded as the first metropolitan park in São Paulo. It was built in 1954 as the city laid claim to the title of "modern metropolis". Sprawling across an area of $1,584,000 \mathrm{~m}^{2}$ in the vicinity of wealthy neighborhoods, the park boasts a complex of buildings designed by Oscar Niemeyer for
\end{abstract}

1. Profesora Doutora do Departamento de Projeto da Faculdade de Arquitetura e Urbanismo da Universidade de São Paulo. E-mail: <anabarone@usp.br> 
2. Anhembi, p. 294 , abr 1953. commemorative exhibitions. Its construction gave rise to a number of protests gathered around a group with direct representation in several institutions and mass media. Subsequently, however, the opposition was completely silenced not only by the social agents involved in the process but also by the literature published on the subject. In this paper, we try to raise a few questions about the said opposition in an effort to set a counterpoint to the commemorative nature of the events associated with the city's foundation, and thereby look beyond the celebration and acclamation of its progress. Our investigation brings to light an arena of conflicts and disputes, suggesting that there was no direct connection between the celebration of the city's anniversary and the modern design of the pavilions in lbirapuera Park at the time, but rather a series of political clashes of great import for urban planning in São Paulo that are worth revisiting.

KEYWORDS: Urban planning in São Paulo. Creation of Ibirapuera Park. Opposition to the pavilions of Ibirapuera Park. Oscar Niemeyer. 4th centenary of São Paulo.

"A construção desses palácios significa o desaparecimento definitivo do Ibirapuera como parque público."2

Introdução

São Paulo é uma cidade carente de espaços livres. A constatação não é recente: está posta em debate pelos urbanistas pelo menos desde meados da década de 1920, quando se cogitou, pela primeira vez, a criação de um grande parque público que atendesse a todos os seus habitantes. Tratava-se do parque Ibirapuera. Entretanto, ele só seria implantado de fato em 1954, por ocasião do IV Centenário de fundação da cidade.

parque lbirapuera é uma das obras públicas mais eloquentes de seu tempo. Localizado junto a um dos setores mais nobres de São Paulo (Figura 1), foi criado em um momento em que a cidade arvorava a condição de "metrópole moderna", em pleno vigor do desenvolvimento. Com 1.584.000 m², o parque foi destinado ao lazer e à cultura da população urbana. $\bigcirc$ industrial Ciccillo Matarazzo, na condição de presidente da Comissão dos festejos de comemoração do IV Centenário, foi responsável por efetivar sua construção, inclusive em termos dos ajustes políticos necessários.

A história de sua criação incluiu a construção de um conjunto de edifícios desenhados por Oscar Niemeyer, com o fim de abrigar as exposições da Feira Internacional da Indústria de São Paulo. Entretanto, a ocupação do parque por esses pavilhões envolveu, na época, uma forte oposição. Um dos maiores representantes dessa oposição foi o jornal $\bigcirc$ Estado de São Paulo, cujas argumentações estavam ancoradas nas discussões da mais veemente organização de urbanistas da cidade naquele momento, a Sociedade Amigos da Cidade. No entanto, posteriormente, essa oposição foi totalmente silenciada, tanto pelos próprios agentes sociais envolvidos no processo quanto pela bibliografia sobre o assunto. 


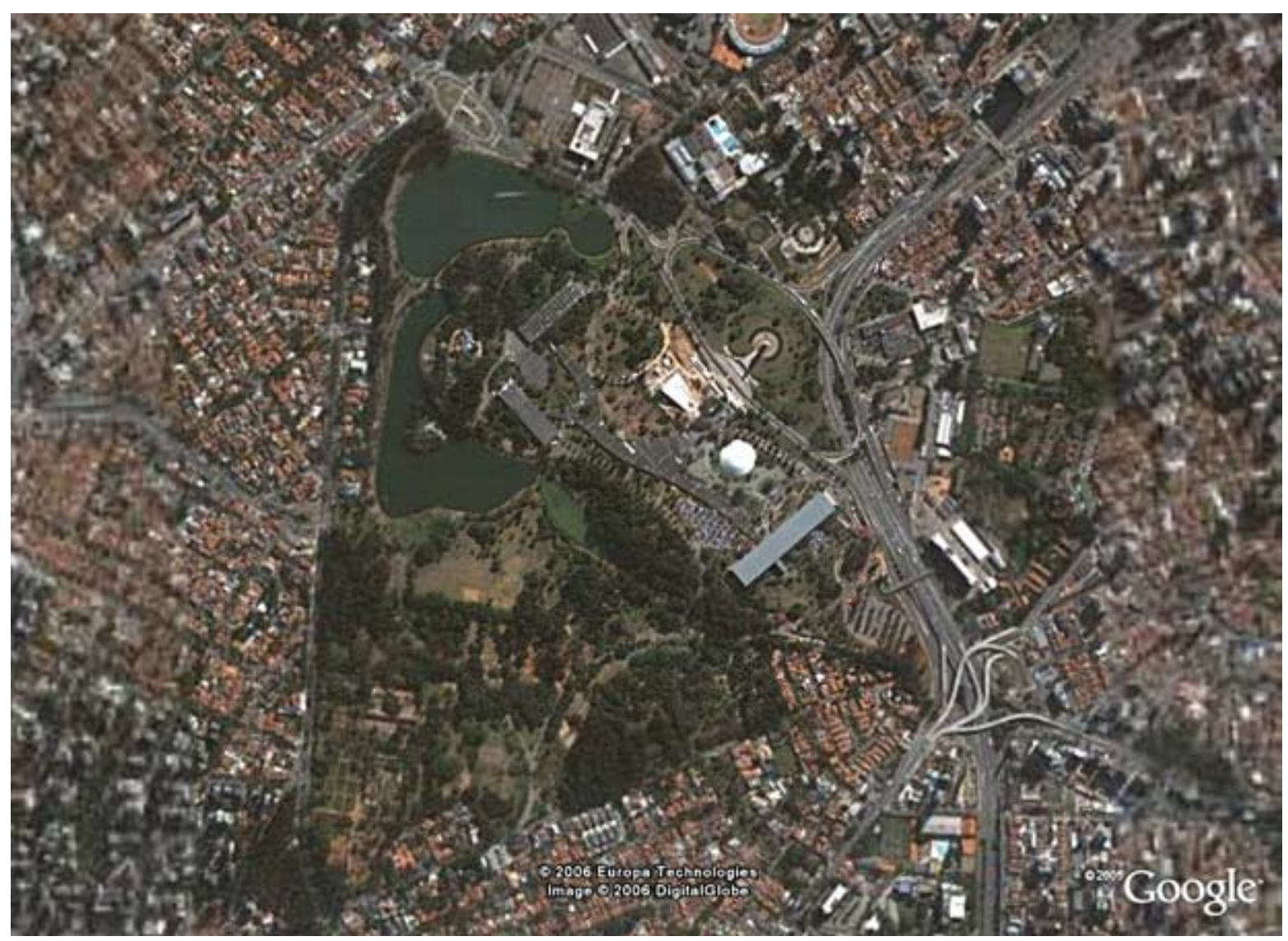

1 - Vista aérea do Parque Ibirapuera, em que é possível observar os edifícios remanescentes da exposicão do IV Centenário e os bairros elitizados de seu entorno.Google Earth, acesso em julho de 2006.

De modo geral, a bibliografia que trata da história de criação do parque tem destacado enfaticamente o caráter comemorativo do momento histórico da cidade e a modernidade da concepção do parque, associando as duas noções. Dessa leitura, decorre que a modernidade do projeto emerge como fruto da pujança da capital paulistana, fundindo a obra ao próprio objeto de comemoração, a cidade em si.

Dois trabalhos importantes focalizam a relevância do Ibirapuera como elemento emblemático da inserção da cidade na modernidade, constituindo referências fundamentais para o estudo da criação do parque. No entanto, ao compreenderem-no como símbolo dessa inserção, ambos se tornam, em seus próprios pressupostos, entusiastas do caráter comemorativo do momento histórico em foco, passando ao largo das polêmicas e enfrentamentos que tomaram corpo na cidade em relação à sua ocupação. $O$ texto de Regina Meyer $^{3}$ situa a criação do parque em um "momento de inflexão" da história da cidade, definido pela consolidação da metrópole, no período em que São Paulo se torna o maior centro industrial do país; o de Maria Arminda Arruda 4 analisa o desenvolvimento e o poder econômico de São Paulo, no âmbito nacional, por meio do estudo das
3. Ver Regina Meyer (1991).

4. Ver Maria Arminda Arruda (2001).

Annals of Museu Paulista. v. 17. n.2. July - Dec. 2009. 
5. Ver Paulo C. G. Marins (2003). obras urbanas, intelectuais e culturais produzidas na cidade em meados do século XX. Ambos imprimem um tom de celebração ao desenvolvimento e à modernidade de São Paulo presente no contexto da criação do parque, replicando a euforia paulistana daquele momento.

A perspectiva deste artigo desloca o enfoque do eixo comemorativo para fazer emergir outros aspectos envolvidos no processo. $\bigcirc$ foco ora escolhido privilegia a oposição levantada contra os pavilhões do Ibirapuera, com vistas a estabelecer um contraponto ao caráter comemorativo da fundação da cidade, permitindo a superação do olhar celebratório e de elogio do progresso paulistano, baseado na pujança econômica da cidade. A investigação sobre a oposição ao projeto do parque denunciou conflitos de posição, delineando um campo de disputas e indicando que não havia continuidade entre a celebração do aniversário da cidade e a modernidade dos pavilhões do Ibirapuera. Ao contrário, o que havia era uma série de embates políticos de relevância para o urbanismo em São Paulo, que merecem ser recuperados.

No sentido da crítica em relação ao olhar celebratório contido nos festejos de 1954, vale lembrar o esforço já realizado por Marins 5 , em artigo que situa os pavilhões do lbirapuera entre os monumentos erguidos no Parque no mesmo período: o Monumento às Bandeiras, de 1953, e o Monumento Constitucionalista, de 1955. A superação do olhar celebratório está presente nas perguntas que fundamentam seu texto: o que se celebra? $\bigcirc$ que se homenageia? De que matéria se constitui a identidade paulista e seu conteúdo simbólico? Marins insere esses monumentos no contexto da construção simbólica da identidade paulista, forjando, por meio deles, uma narrativa que vai da invenção da imagem do bandeirante como herói à diluição do nexo entre o passado e o futuro, por meio da consolidação da metrópole moderna e cosmopolita em São Paulo. Ao situar a figura do bandeirante como mito de origem dessa identidade, o autor constitui um marco simbólico de referência para os monumentos analisados. Assim, de acordo com sua interpretação, o Monumento às Bandeiras seria a celebração do próprio mito, com todas as nuances dessa apropriação, e o Monumento Constitucionalista, sua atualização, na figura do soldado constitucionalista. Nessa leitura, os pavilhões do Ibirapuera situam-se justamente no ponto de inflexão do campo de representação simbólica da metrópole: o momento em que a cidade se define de maneira essencialmente urbana e cosmopolita, voltando-se para o futuro, desgarrando-se do passado colonial e bandeirante e superando, portanto, seu mito de origem.

As polêmicas em torno da criação do parque

Os terrenos da Várzea do lbirapuera eram terras devolutas tornadas públicas em 1891, por cessão do ministério da Agricultura ao município de São Paulo. A decisão de ali se implantar um parque público foi levada à Câmara Municipal em 1926. A partir dessa data, houve um intenso conflito - entre o poder público e interesses particulares de diversas naturezas - pela propriedade 
de frações da gleba, com contestações judiciais que ocorrem até hojeb. $\bigcirc$ parque só foi efetivamente implantado 28 anos depois, em 1954, quando da comemoração do IV Centenário da cidade.

Desde 1948, a comemoração do IV Centenário era uma preocupação do poder público municipal. Em 1951, Lucas Nogueira Garcez, governador do Estado de São Paulo, apoiado pelo prefeito Armando de Arruda Pereira, designou Francisco Matarazzo Sobrinho, o Ciccillo, para exercer a função de coordenador geral das atividades relativas à comemoração do IV Centenário ${ }^{7}$. Ciccillo foi o grande responsável pela escolha do local onde seriam realizados os festejos. Foi ele quem pressionou para que os eventos comemorativos se concentrassem no Ibirapuera, dando assim o argumento que faltava para que, em cerca de um ano e meio, o primeiro parque metropolitano da cidade fosse implantado e aberto ao público.

Sem dúvida, as decisões tomadas pela comissão encabeçada por Ciccillo não foram colocadas em prática sem polêmica e disputas. Muita gente era contra a ideia dos festejos comemorativos no parque. Eram cogitados outros lugares da cidade para sediar o evento, como o Anhembi, na zona norte, ou o futuro campus da Universidade de São Paulo, a oeste. Uma espécie de disputa estava sendo travada entre aqueles que defendiam que as comemorações deveriam acontecer no novo campus universitário e os que queriam um novo espaço construído especialmente para o evento. $\bigcirc$ próprio cargo de presidente da Comissão foi disputado entre Ciccillo e Christiano Stockler das Neves, partidário da localização dos festejos em outro local e defensor de uma outra ideia de modernidade para o lbirapuera, apoiada nos valores tradicionais das Beaux-Arts e do ecletismo ${ }^{8}$.

Com o andamento dos trabalhos da Comissão, as polêmicas assumiram diferentes formas. $\bigcirc$ principal motivo do ataque ao projeto foi a presença, na área do parque, dos edifícios de exposições. Especificamente contra a edificação dos pavilhões, o período entre 1950 e 1953 registrou inúmeras investidas, em diversos meios de divulgação. Um dos artigos mais contundentes foi publicado em 1953, na revista Anhembi. Editada pelo jurista, jornalista e antropólogo Paulo Duarte entre 1950 e 1962, a revista difundia artigos de intelectuais ligados à Universidade de São Paulo. O artigo sobre o parque, não assinado, não poupava adjetivos pejorativos:

Consumaram-se os incríveis atentados resolvidos pela Comissão de Executivos do IV Centenário contra o Parque do Ibirapuera. Foi inútil o clamor público, inúteis os protestos de urbanistas, de entidades como a dos Amigos da Cidade (que aliás, parou logo a sua voz) e a maioria da imprensa de S. Paulo. Todos os homens de bom senso levantaram-se contra essa acanhada resolução de fazer-se naquele parque a exposição do centenário e erigirem-se as enormes construções ali projetadas?

$\bigcirc$ jornalista anônimo de Anhembi deixava claro qual era o problema: a construção de pavilhões permanentes no parque. "Inicialmente afirmava-se que
6. Ver Ana C. C. Barone (2007, p. 16-45).

7. Ofício, 26 jun. 1951, Arquivo Histórico Municipal Washington Luis, fundo IV Centenário, caixa 85 , processo n. 173 .

8. Ver Fabiano L. Oliveira (2003).

9. Anhembi, p. 293-295, abr. 1953; grifos nossos. 
10. Ibidem.

11. Ibidem.

12. Ver Ana C. C. Barone (2007, p. 75-86) a totalidade das construções seriam provisórias, sendo o parque devolvido ao público lindamente urbanizado e livre de qualquer construção" 10 .

O jornalista sugeria que os pavilhões fossem destruídos após as comemorações, com a finalidade de recuperar a vegetação do parque. Defendia um Ibirapuera exclusivamente verde, "lindamente urbanizado" e "livre de qualquer construção". Também sugeria que a feira fosse construída "noutro local, e não num dos raros logradouros com que conta a cidade em seu perímetro urbano".

O autor fazia crer que não estava sozinho em sua opinião: pelo contrário, contava com o "clamor público" e o apoio dos "urbanistas", de "entidades", da "maioria da imprensa"; acusava a comissão de ir "contra a opinião pública, contra o parecer de entidades culturais, contra o parecer da melhor imprensa" ${ }^{11}$. Posteriormente à construção dos pavilhões, entretanto, não se teve mais notícia de tão fervorosa resistência. Quem seriam, então, esses interlocutores singelamente ocultados, mas tão ativos e sonoros nos seus clamores e protestos? Como tal pluralidade de vozes calou-se tão completamente logo em seguida?

Algumas fontes de documentação do período permitem identificar certos atores que se pronunciavam, em diferentes meios institucionais, no sentido dessa oposição. Assim, pode-se supor, a partir dessas fontes, que os "urbanistas" citados pelo jornalista de Anhembi fossem os membros da Sociedade Amigos da Cidade (SAC) que, no período em que se elaborava o projeto da Feira Internacional da Indústria no novo parque, atuaram no sentido de dissuadir as autoridades e o público. A "maioria da imprensa" pode ser exemplificada pelo jornal O Estado de São Paulo (OESP), que, através da publicação de diversos artigos, mantinha sua posição de defesa de um parque isento de construções. Entre as "entidades", além da própria SAC, foi localizada também uma instituição denominada Sociedade de Proteção da Natureza, que, nesse período, fez uma campanha em favor dos espaços verdes da cidade e, especificamente, de um parque exclusivamente verde no lbirapuera. Curiosa, entretanto, para além da presença desses interlocutores no debate sobre o parque e a cidade, é a estreita articulação existente entre eles, que veremos a seguir.

\section{A posição da SAC}

Na SAC, a defesa de um parque isento de construções no terreno do Ibirapuera já vinha ocorrendo desde o período de sua fundação. Tal questão era levantada sempre que surgia o risco de implantação de edifícios no local. Foi o caso, por exemplo, da investida contra a instalação do hipódromo e do aeroporto, na década de 1930'12. A partir de 1950, em função da ameaça representada pela exposição do IV Centenário, o Parque Ibirapuera voltava a ser assunto central nas reuniões da SAC.

Naquele ano, a Sociedade publicou um texto de Goffredo da Silva 
Telles defendendo a implantação definitiva de um parque nos terrenos do Ibirapuera. O documento é, na verdade, uma carta de 1947, endereçada a Christiano Stockler das Neves, prefeito da cidade, pedindo para que não fossem "desvirtuados os fins a que se destinam as terras de lbirapuera"13.

Telles colocava a questão em termos da retomada de uma preocupação "que já se apresentava com aspectos de real gravidade aos olhos dos observadores de outrora" 14 . O jurista inseria o problema no contexto de uma evolução histórica, no sentido da criação do parque, pautada na atuação de diversos prefeitos, como Pires do Rio e Fábio Prado ${ }^{15}$. O texto sustentava-se no "plano elevado em que os técnicos de administração de cidades têm colocado a questão das reservas e distribuição de áreas livres para logradouros ajardinados ou florestados de uso público"16.

tratamento da questão das áreas livres era colocado no plano do debate internacional, comparando a situação de São Paulo com cidades da Europa e dos Estados Unidos. São Paulo era descrita como "uma das mais desfavorecidas das grandes aglomerações humanas", uma cidade "privada de logradouros públicos" e carente de "zonas de respiração". O ex-prefeito lembrava que a "cidade de tipo ralo", como São Paulo era descrita, estava adensando-se a cada dia, tendendo a piorar, dada a acentuação do "adensamento das construções e o congestionamento dos bairros", o "caráter cada vez mais tumultuoso da vida moderna" e o aumento da "insalubridade do meio urbano" 17 .

Em termos da perspectiva de crescimento, a população urbana deveria quadruplicar em vinte anos. Com o aumento previsto, a cidade passaria a ter o índice infame de um quarto de metro quadrado de área livre por habitante, sendo necessário multiplicar em 24 ou 25 vezes as áreas de parques públicos. Perspectiva flagrante, tendo em vista as parcas áreas livres disponíveis para esse fim. Telles evocava, assim, o "imperioso dever [...] de melhorar a situação de nossa Capital no que diz respeito a seus parques públicos"18.

Subjacente ao discurso publicado pela SAC, jazia uma concepção de "área livre" forjada de uma reinterpretação da cidade-jardim inglesa. Segundo o autor, a população atirava-se "aos arrabaldes e subúrbios distantes, em busca de um refrigério que the é negado no borborinho da Capital". Telles pontuava que "os parques urbanos não constituem simples motivo decorativo das cidades, mas condição de bem-estar e, sobretudo, fator importante de saúde pública" 19 .

Nesse discurso sobre a cidade, as "áreas livres" assumem uma importância fundamental. Nele, a rarefação da cidade, à medida que se afastava do centro, era desejável para os urbanistas e desejada pelos habitantes. Quanto mais áreas verdes em seu redor, mais salubre e adequada a um padrão urbanístico moderno. Para atingir essa eficiência, era imperativa uma distribuição homogênea de espaços livres nos bairros em torno do centro congestionado, visando "o arejamento dos prédios, de áreas abertas para a ventilação das ruas, de refúgios frescos para o descanso, o exercício esportivo, o recreio e o conforto da população" 20 .
13. Ver Goffredo T. da Silva Telles (1950)

14. Ibidem.

15. Ver Maria Ruth Amaral de Sampaio (1999).

16. Ver Goffredo T. da Silva Telles: (1950, p. 5).

17. Ibidem.

18. Ibidem.

19. Idem, p. 6

20. Idem, p. 7 
21. Ver o livro de atas da Sociedade Amigos da Cidade de 1951 a 1955.

22. OESP, p. 4, $10 \mathrm{abr}$. 1951.

23. Ibidem.

24. Ibidem.

25. Ibidem.
Vale ressaltar que, no contexto da SAC, a publicação do texto de Telles não foi uma ação isolada em relação ao parque. Foi, antes, expressão de um conjunto de discussões promovidas pelo conselho da instituição, registradas em suas atas, com o propósito de marcar uma posição de defesa do terreno desprovido de construções, a fim de constituir-se, naquele local, um parque inteiramente verde ${ }^{21}$.

Os argumentos desenvolvidos pelos urbanistas da SAC eram reproduzidos, também, em outros meios. Exemplo disso são as discussões da Câmara Municipal, publicadas no Estado:

Como o objetivo de mostrar a necessidade de ser construído em São Paulo um parque público e ainda sobre a conveniência de se aproveitar o Parque lbirapuera, o vereador Francisco Assunção Ladeira pronunciou entre outras coisas, as seguintes palavras: "São Paulo é uma cidade de mais de dois milhões de habitantes e que não possui para a sua população um parque público de recreação a exemplo do que são para os parisienses o Bois de Boulogne ou para o portenho o Parque de Palermo, parques que constituem para a grande massa da população uma possibilidade de fuga à vida malsã dos grandes centros urbanos, das grandes aglomerações industriais"22.

problema dos parques públicos era percebido na Câmara como uma questão de necessidade de contato com a natureza.

A necessidade de um refúgio desta natureza, onde a população cansada da cidade possa em seus dias de folga encontrar-se com a natureza, com o sol, com o ar puro, fica bem evidenciada a quem quer que transite pelo chamado Parque lbirapuera aos domingos ou dias feriados. Nos dias de calor, muita gente sente desejo de fugir para viver algumas horas em praias ou à sombra das árvores ${ }^{23}$.

Além disso, uma das maneiras de retratar o problema era apontar o abandono em que se encontrava o parque, um projeto incompleto, jamais terminado. "Muitos prefeitos já passaram pela Capital e nenhum se lembrou de tomar uma providência concreta para o aproveitamento do local. Fala-se em estudos, planos, etc. Mas a verdade é que isso não passa de conversa, e o Ibirapuera continua esquecido, abandonado e insalubre." 24.

Frisando o estado de abandono do projeto, a argumentação do vereador ressaltava também os perigos do uso público da área:

Comumente, vemos homens e mulheres sentados ao longo da avenida Central existente no Parque Ibirapuera. Crianças com patins ou bicicletas ali procuram distração e outros banham-se em uma infecta e perigosa lagoa ali existente. Não seria demais repisar aqui os perigos que o local oferece como se encontra, ressaltando o tráfego intenso pelas avenidas por onde transitam inúmeros automóveis que se dirigem a Santo Amaro. Quanto à lagoa, tem ela tragado a vida a muitas crianças, sendo objeto até de uma portaria recente do juiz de Menores, proibindo sua utilização25. 
Finalmente, retomava-se a necessidade dos espaços livres em cidades grandes, e o lbirapuera era lembrado como o único parque de grande porte da cidade.

Há necessidade urgente de construir-se em São Paulo um parque público e lugar nenhum melhor que a referida área para a instalação desse parque. São Paulo possui recantos como Santo Amaro ou o Horto Florestal mas, são passeios para pessoas que possuem automóveis, para as classes mais abastadas, porque na verdade a população pobre tem dificuldade enorme de atingir esses locais, quer pela dificuldade de transporte ou por outro motivo 26 .

IV Centenário era visto como uma oportunidade para "dotar São Paulo de um parque [pois] aqui serão realizadas grandes festas e para cá virão turistas de todo o mundo. Fala-se em aproveitar essa área para a construção de pavilhões, exposições, etc. Seria pois o caso de ser feito um estudo imediato de aproveitamento desse parque, conjugando-se ambos os interesses" 27.

Estado de São Paulo e a defesa do parque inteiramente verde

No mesmo período, surgiram no Estado diversas matérias sobre os parques e jardins de São Paulo, evidência de uma valorização dos espaços verdes da cidade por parte daquele periódico. Em 1951, uma série de cinco artigos foi publicada, enfatizando a importância das áreas livres para o descanso e o recreio da população ${ }^{28}$. Os artigos falavam de São Paulo como uma cidade que crescia sem planejamento. "Ninguém previu o crescimento vertiginoso por que iria passar, em particular nos últimos 50 anos." 29 . Essa condição produzia um problema considerado central: os parques existentes eram "poucos e maltratados" e a "numerosa população" via-se "na impossibilidade de gozar alguns momentos de prazer e recreio em domingos e feriados" 30 .

Dando continuidade à sua postura de apoio ao controle e à regulação do crescimento urbano - e ensejando uma cidade descongestionada, em consonância com as propostas da SAC -, o Estado pronunciava-se no sentido da defesa do parque exclusivamente verde. $\bigcirc$ Ibirapuera era fundamental, pois seria o único parque de porte da cidade. No entanto, não estava implantado. Justamente no momento em que se decidia, enfim, construir o parque, escrevia-se sobre ele:

foi esquecido e abandonado. Podendo construir um dos recantos mais aprazíveis de S. Paulo resume-se, na prática, num serviço de passagem: mero ponto de ligação aos que demandam Congonhas ou procuram atingir o centro da cidade, através da 9 de julho ou da Brigadeiro Luis Antônio. No mais, sua vasta área, quase um milhão de metros quadrados, é um capinzal desolador, com duas enormes manchas de água estagnada ${ }^{31}$.

A partir de 1952, o jornal publicou outra série sobre os espaços livres da cidade, incluindo o parque do lpiranga, a área de Guarapiranga, os bosques
26. Ibidem.

27. Ibidem.

28. Idem, p. 9, 3 jul. 1951; p. 9,8 jul. $1951 ;$ p. 7,11 jul. 1951 ; p. 9,15 jul. 1951 ; p. 8 , 18 jul. 1951.

29. Idem, 3 jul. 1951.

30. Ibidem.

31. Ibidem. 
32. Idem, p. 13, 9 mar 1952.

33. Ibidem.

34. Ibidem.

35. Idem, p. 8, 20 mar. 1952.

36. Idem, 9 mar. 1952. de Santo Amaro e Jabaquara, etc. Os artigos faziam parte da rubrica Recantos pitorescos da cidade, ilustrada por grandes fotos, mostrando vegetação exuberante, lagoas e detalhes paisagísticos.

No contexto de defesa dos espaços livres como lugares pitorescos, o Ibirapuera era noticiado a partir da ameaça de sua extinção. Tais artigos representavam uma crítica frontal ao projeto, da Comissão do IV Centenário, de instalar no parque os pavilhões de exposições da Feira Internacional. "É de lamentar-se que a Comissão do IV Centenário persista no propósito de comemorar a grande data paulistana mutilando a cidade, destruindo a esperança há tanto tempo acalantada pela população, de ver transformado o lbirapuera num parque público, o único, aliás, da Capital." ${ }^{2}$.

Tal como sugeria o artigo de Anhembi, os opositores defendiam a localização dos festejos em outro local, como, por exemplo, "a magnífica área reservada à futura cidade universitária e o bairro de Interlagos" 33 . Para eles, "nada compensaria a cidade da privação que se the quer impor, de seu único parque público"34. O grupo queria ver a Comissão empenhada "na execução dos velhos planos de sua transformação num verdadeiro parque, quebrando, com sua vegetação, a aridez da Capital" 35 .

O Ibirapuera era descrito como "derradeiro reduto paulistano de vegetação e frescor", em contraponto aos planos da Comissão, tidos como uma "infeliz ideia" 36 . A oposição criticava também os edifícios, referindo-se a eles

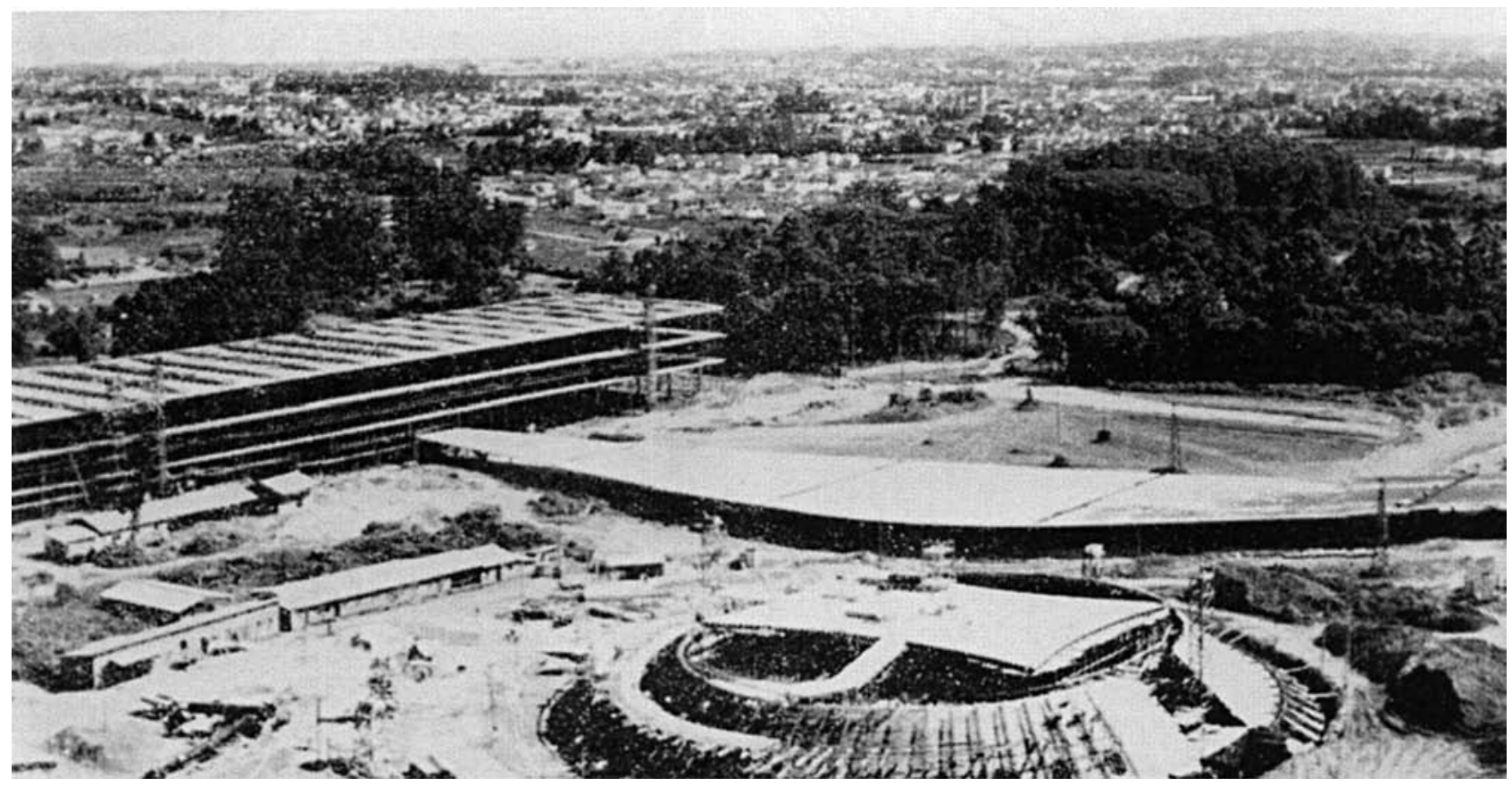

Figura 2 - Vista aérea da construção da marquise e pavilhões do lbirapuera em 1953, em que se nota a substituição do bosque de eucaliptos pelo conjunto de edifícios. Fotografia de Boer, Copyright Casa Guilherme de Almeida, publicado em Instituto Cultural Itaú. Cadernos da cidade de São Paulo: Parque do Ibirapuera. São Paulo: ICl, 1997. 
como "os barracões provisórios com que se pretende atravancar o parque e os dois grandes blocos de cimento armado que se projetam construir" 37 .

Em 1953, Lourival Gomes Machado pronunciava-se contra a estratégia de erguer um conjunto moderno, para abafar o corte da vegetação, que ele via como um problema maior (Figura 2):

São abundantes e entusiasmados os comentários sobre a primeira parte do conjunto arquitetônico ideado pelo Sr. Oscar Niemeyer para fazer esquecer a destruição do último punhado, inculto e belo, de vegetação do Parque, ou melhor, do que foi o Parque Ibirapuera. Os imensos planos envidraçados a flutuar por sobre o espaço em que a longa serpentina de concreto se flexiona molemente, muito embora nada digam da utilização humana e social da obra, já bastam, contudo, para justificar o maravilhamento geral [...]. Não é pequeno o número dos que perceberam o que isso representa para o Brasil. ${ }^{38}$

Durante algum tempo, o debate foi sustentado em termos de pavilhões provisórios versus pavilhões permanentes: "assegura a comissão do IV Centenário que os edifícios serão provisórios. Mas temos motivos, os paulistanos, para desconfiar das coisas provisórias, que têm, nessa desordenada capital, notável tendência para eternizar-se" 39 (Figura 3).

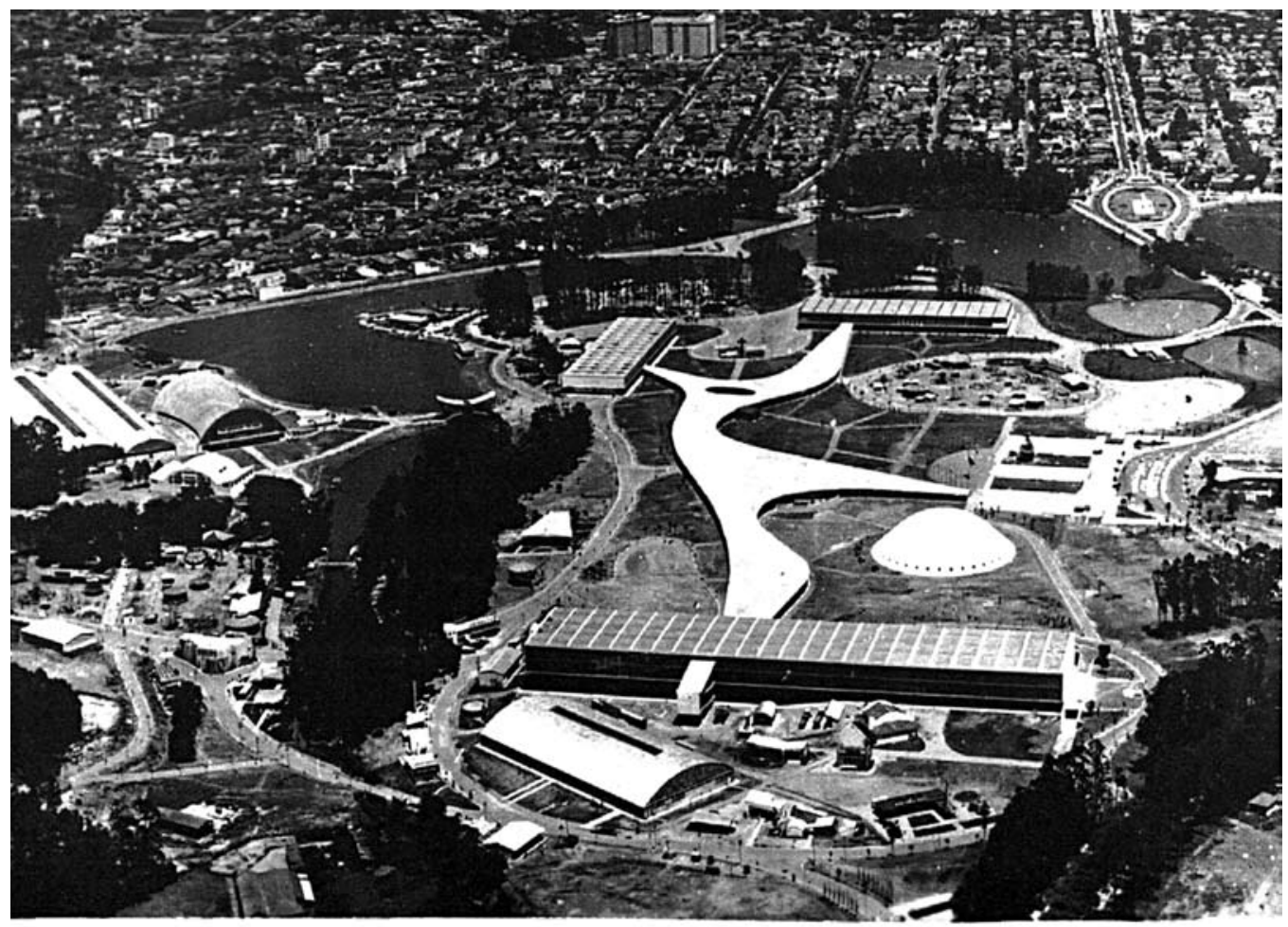

Exposição Ibirapuera S. Paulo-4 Centenario 1954
37. Idem, p. 8, 20 mar. 1952.

38. .Idem, 15 dez. 1953

39. Idem, 9 mar. 1952

Figura 3 - Vista aérea do Parque Ibirapuera em 1954, publicada em cartão postal, em que é possível ver, além dos edifícios permanentes projetados por Niemeyer, os pavilhões provisórios demolidos após os festejos. Acervo de João Emílio Gerodetti, reproduzido em Mariano, 2003. 
40. Idem, 11 maio 1952.

41. Idem, 3 jul. 1952.

42. Ibidem.

43. Idem, 20 mar. 1952.

44. Idem, 11 maio 1952

45. Ibidem.

As matérias do jornal apresentavam as posturas municipais como atos criminais: a terminologia utilizada incluía "mutilação", "atentado", "destruição", "desvirtuação" 40 . Contra a possibilidade do parque exclusivamente verde, a proposta da exposição internacional não passava de "uma dezena de blocos de vidro e cimento armado de um mau gosto doloroso", fazendo parte do "plano de mutilação do Ibirapuera", "plano absurdo e criminoso" de "desvirtuamento dos fins a que se destina aquele logradouro", "um projeto contra o qual se levanta o clamor da opinião pública"4l.

A contrariedade era clara para os antagonistas: quanto mais construções, menos vegetação. Anunciava-se a "derrubada das poucas árvores existentes no lbirapuera [...] Vão cedendo, à força do machado, as poucas aleias ali existentes, implantando-se, nas clareiras abertas, os barracões iniciais dos edifícios com que se entulhará aquela área de terra, desviando-a dos fins para que fora, há vinte anos, reservada pela administração pública"42.

Em seguida, o jornal passou a publicar acusações diretas contra a Comissão. "Pouco se sabe ainda do desenvolvimento dos trabalhos da autarquia encarregada de organizar as comemorações, em 1954, do quarto centenário da fundação da cidade". Ainda que não se pudesse "negar apoio à ideia" de "constituir um motivo a mais de atração aos turistas que nos pretendem visitar", os opositores começavam a achar "escasso o tempo para um empreendimento desse vulto" e a "considerar a impossibilidade de inaugurar, dentro de menos de dois anos, uma grande exposição internacional"43.

Os argumentos no jornal afinavam-se à medida que progrediam. Apoiados pelo parecer dos urbanistas, os opositores lançavam mão da racionalidade técnica do discurso:

Desde que se projetou esse empreendimento, a população paulistana tem procurado revelar, por todos os meios, o seu desejo de ver realizado aquele plano, cuja execução viria corrigir uma das maiores lacunas urbanísticas da Capital. Entretanto, continua a cidade a crescer: quase duplicou sua população nesta última década! - sem que a Prefeitura se dispusesse a conceder verbas suficientes ao preparo daquele logradouro, que viria corrigir a aridez da já imensa área urbana da Capita ${ }^{44}$.

Tal como no texto de Telles, o problema foi colocado sob uma perspectiva histórica:

Enquanto o mal não ia além dessa displicência dos poderes públicos municipais, ainda nos restava a esperança de que um bom governo atendesse, no futuro, a esse desejo da população. Ultimamente, porém, começam a multiplicar-se os projetos de aproveitamento do lbirapuera, não para a construção de um parque, mas para outros fins que se afastariam, definitivamente, da Comissão Organizadora dos Festejos do IV Centenário da Cidade. Infelizmente, dizemos, porque, dispondo-se a desviar aquela área de terras dos fins para que foi reservada, ofereceu a autarquia deplorável demonstração de insensibilidade a uma das mais gritantes falhas da cidade, cujos problemas a comissão não tem o direito de desconhecer ${ }^{45}$. 
Ibirapuera era descrito como "última possibilidade que the resta [à cidade] de possuir um parque à altura de sua grandeza" 46 . Finalmente, indicava que se tratavam de "obras prejudiciais ao urbanismo da Capital e combatidas pela unanimidade da população"47, identificando o próprio grupo de oposição com o conjunto da opinião pública geral. "Insurgiu-se a opinião pública, veementemente, contra os planos de retalhamento do lbirapuera, seja para a realização, ali, de uma exposição internacional, seja para a construção de alguns blocos de cimento armado" 48 .

Os opositores se auto-identificavam como "resistência da opinião pública", constituindo a "veemente oposição encontrada pelo projeto", apresentando-se como porta-vozes da "antipatia do público por esse atentado" 49 .

Uma campanha da sociedade civil em defesa do parque inteiramente verde

Foi nesse contexto que se instituiu, em setembro de 1951, uma campanha da Sociedade de Proteção da Natureza a favor da preservação do parque e contra a construção dos pavilhões de exposições do IV Centenário, tentando impugnar o projeto. A campanha mencionava que a sociedade havia tomado conhecimento, pela Folha da Manhã, de 7 de setembro de 1951, que - Parque lbirapuera estava "indicado para uma infinidade de construções destinadas à exposição comemorativa do IV Centenário da cidade". Os manifestantes argumentavam que

Com muito mais de 2 milhões de $\mathrm{m}^{2}$, desapropriado para ser o único parque, verdadeiramente parque de São Paulo - as constantes mutilações que sofreu reduziram sua área ao pauperismo de menos de 1 milhão e meio de $\mathrm{m}^{2}$, para a cidade que no centenário terá 2,5 milhões de habitantes, com pouco mais de meio $\mathrm{m}^{2}$ para cada pessoa! ${ }^{50}$.

Além disso, lembravam que "por leis até imperativas, São Paulo está crescendo, não só em extensão, mas em altura, com incontáveis arranha-céus" ${ }^{51}$, para frisar a importância da preservação de áreas livres na cidade. A campanha indicava a contradição da cidade, sem enaltecer o seu crescimento, mas vendo-o como ameaça à qualidade urbana e como obstáculo para a abertura de espaços livres.

O documento citava, ainda, a comparação feita por Goffredo da Silva Telles, cotejando São Paulo com as grandes cidades da América do Norte e Europa, dizendo que as menos arborizadas possuíam pelo menos 8 vezes mais áreas verdes que São Paulo, chegando a 20, 30 e 50 vezes. E indicava que Telles referia-se à área do parque como "pulmão verde".

Finalmente, criticava-se "toda e qualquer construção que se faça, por mais arquitetônica que seja"52, pontuando uma diferenciação: de um lado, os
46. Idem, 3 jul. 1952.

47. Ibidem.

48. Idem, 11 maio 1952.

49. Idem, 3 jul. 1952.

50. Ver Carta, 13 set. 1951, à

Comissão do IV Centenário,

fundo IV Centenário, série Gabinete, processo 215.

51. Ibidem.

52. Ibidem; grifo nosso. 


\section{Ibidem.}

55. SAC, Livro de Atas, 17 set. 1951 a 14 set. 1955 , reunião de 13 fev. 1952, fl. 1314.

56. Ibidem.

57. Idem, reunião de 20 ago. 1952, fl. 29

58. Idem, reunião de 25 jun. 1952, fl. 26. arquitetos desenvolviam uma linguagem moderna para os novos edifícios; do outro, os defensores dos espaços livres, urbanistas, engenheiros, advogados e outros profissionais, defendiam as áreas urbanas arborizadas como "pulmão verde da cidade", contrapondo as áreas vegetadas às áreas ocupadas pelos blocos de concreto.

O Estado de São Paulo também noticiou a campanha: "A Campanha de proteção à natureza [...] faz veemente apelo no sentido de não ser dado encaminhamento a um projeto de lei há dias apresentado [... ] indicando o Parque Ibirapuera para construções destinadas à Exposição comemorativa do 4.? Centenário da cidade" 53 .

Segundo o jornal, a campanha relembrava o estado de abandono do parque e a ameaça de se fazer ocupar pelos edifícios do IV Centenário: "e o malsinado Ibirapuera, tantas vezes reduzido e nunca ajardinado, como fora previsto pela municipalidade, e que agora, pelo projeto apresentado a essa nobre assembleia, ver-se-á praticamente extinto, tal o volume das construções projetadas" 54 .

O processo conciliatório

$\bigcirc$ primeiro passo para a conciliação entre os opositores e a comissão que implementava o conjunto destinado à Feira Internacional foi dado na SAC, por um associado que também fazia parte da equipe de projeto do Parque Ibirapuera: Eduardo Kneese de Mello. O arquiteto buscava legitimar a presença dos edifícios no parque, "declarando ter feito parte de uma Comissão que, durante três meses, estudou o projeto dos pavilhões, bem como de sua localização, esclarecendo que os seus membros sempre consideraram a conservação do parque e das suas árvores, idealizando até a plantação de outras" 55 .

Kneese de Mello propôs uma visita da SAC à Comissão, "para que a Sociedade pudesse ficar melhor esclarecida sobre o assunto"56. Ainda assim, os urbanistas reiteraram sua posição: "O sr. Presidente [...] submeteu a debate a conveniência da SAC publicar um manifesto esclarecendo a opinião pública de S. Paulo a respeito de sua atitude em defesa do Ibirapuera, bem como manifestando os inúmeros erros em que incide a Comissão dos festejos, prejudiciais ao bom êxito das comemorações e ao interesse público" 57 .

Em nova reunião, foi lida uma entrevista de Ciccillo Matarazzo publicada na imprensa, relativa à escolha do Parque Ibirapuera para sediar a feira industrial, solicitando pormenores do projeto para avaliação pela SAC: "A entrevista em apreço deu ensejo a longos debates por parte dos presentes, manifestando-se a maioria favorável a que a sociedade mantenha o seu ponto de vista já firmado em ocasiões anteriores, isso é, contrário a qualquer utilização daquela gleba municipal que não seja para transformá-la exclusivamente em parque público" 58 . 
Houve também uma polêmica entre a SAC e o prefeito Armando de Arruda Pereira, que teria contestado o objetivo da agremiação, a partir de uma desavença em relação à urbanização do lbirapuera. A SAC defendeu-se dos ataques do prefeito, indicando seus esforços de luta pela "transformação do Ibirapuera num logradouro público adequado às necessidades de São Paulo, destacando-se o fundamentado memorial encaminhado a 14 de maio de 1947 , na presidência do Sr. Goffredo T. da Silva Telles, e publicado em opúsculo sob o título 'São Paulo - Cidade sem parques e sem áreas livres'"59.

A SAC também julgava não estar sendo precipitada "ao se rebelar contra a localização da mostra industrial no lbirapuera, antes de conhecer todos os pormenores do projeto da Autarquia. Fiel ao roteiro traçado, insistiu na imediata urbanização do parque, para ensejar sua entrega ao povo em 1954. O seu ponto de vista, há muito firmado, independia de quaisquer esclarecimentos"60.

O esforço para apaziguar a situação partiu do prefeito e foi registrado nas atas de reunião da SAC:

tendo o sr. Prefeito municipal, na visita feita pela Sociedade, manifestado o desejo de convidá-la a se manifestar, digo, a se fazer representar na Comissão Consultiva dos Festejos do $4^{\circ}$ Centenário, antecipando convite que oportunamente formulará por ofício, o sr. Presidente afirmou que está certo de que esse convite será realmente efetivado, ao contrário do que sucedeu com a promessa feita à diretoria anterior pelo Presidente da Comissão dos festejos ${ }^{61}$.

Com isso, a SAC foi finalmente convidada a participar da Comissão do IV Centenário. Mas a celeuma só foi definitivamente eliminada quando os membros da SAC foram convidados a conhecer as obras dos pavilhões, por meio de um "almoço de confraternização em visita às obras" dando continuidade à sugestão feita por Kneese de Mello ${ }^{62}$. Em uma reunião posterior do conselho, a SAC formalizava uma nova opinião sobre as obras no parque. A construção do planetário tornou-se emblemática dessa mudança:

Em seguida, submeteu ao debate da casa a proposta do dr. José Barbosa de Almeida, presidente em exercício da Comissão do IV Centenário, da Sociedade criar uma campanha para obtenção de recursos financeiros para a construção do planetário, programada para os festejos de 1954, proposta essa formulada durante a visita que a SAC fez às obras da exposição no lbirapuera, a 26 de setembro findo. Após longo debate sobre o assunto, reconheceu-se que o empreendimento é de grande interesse para acidade, sob o ponto de vista cultural, sendo de se desejar que a sua concretização se torne em breve uma realidade ${ }^{63}$

Tal forma de amenizar o conflito indica que pesava para os antagonistas a necessidade de se fazer representar nas instâncias de deliberação sobre os destinos do parque, mais até que sua postura de resistência ao projeto per si. Havia, portanto, antes de mais nada, uma disputa de representação de
59. Ver OESP, 19 jul. 1952

60. Ibidem.

61. SAC, Livro de Atas, reunião de 28 maio 1953 , fl. 50.

62. Idem, reunião de 27 ago. 1953, fl. 58.

63. Idem, reunião de 15 out. 1953, fl. 63. 
poder por trás do conflito. Tal ideia pode ser sustentada pela própria relação simbiótica travada entre os diversos meios institucionais que veicularam as ideias de oposição ao projeto.

Identificando os opositores

Se é certo que o "clamor público", os "urbanistas" e as "entidades" apontadas pelo artigo de Anhembi eram os agentes aqui identificados, devemos observar que não se tratava, como queria transparecer o colunista anônimo, de diversos grupos de opinião com um ideal comum de cidade, mas de um mesmo e único grupo, fartamente representado em múltiplos meios institucionais. Nota-se, por exemplo, que todas as argumentações, seja no jornal, na Sociedade de Proteção à Natureza, na Câmara Municipal, remetem de alguma maneira às discussões encampadas pela Sociedade Amigos da Cidade, legitimada pela figura dos "urbanistas". Nota-se também a reprodução dos mesmos argumentos em todas as formas de manifestação lo parque exclusivamente verde, a sugestão de outros locais para a feira, a polêmica sobre pavilhões provisórios ou permanentes, a perspectiva histórica do problema do lbirapuera nas diferentes administrações municipais etc.), indicando que se tratava dos mesmos agentes sendo pluralmente representados. Os personagens também se repetem, multiplicando sua representação: Goffredo da Silva Telles era membro da SAC e colaborador da campanha de proteção à natureza, patrocinada pela primeira; Anhaia Mello presidia a SAC e tinha suas ideias solidamente representadas no Estado; Christiano das Neves era autor de um projeto arquitetônico para o parque e pleiteava o cargo de presidente da Comissão; e assim por diante. Portanto, as diversas iniciativas registradas nos artigos analisados são, na verdade, originárias de um mesmo grupo que se fazia publicar em diferentes veículos. Apesar de suas divergências internas, tal grupo pode ser identificado como um núcleo do debate que consolidou uma linha de opinião sobre a cidade e o parque naquele momento.

Da mesma forma, a "maioria da imprensa", referida pelo autor, era sobretudo o jornal O Estado de São Paulo, que publicava cada passo da SAC e outras ações cívicas ou políticas no sentido da oposição aos pavilhões, realizando a sua própria discussão do assunto, com uma orientação bastante definida. Outros jornais fizeram coberturas bastante diferentes do processo de criação do Parque Ibirapuera. O Diário de São Paulo, por exemplo, de Assis Chateaubriand, inimigo declarado de Ciccillo Matarazzo - e que portanto poderia usar a oposição ao projeto como um tema de enfraquecimento da figura pública de seu adversário -, nunca mencionou a polêmica sobre a vegetação do parque. Ao contrário, anunciava a Feira Internacional como um grande feito (Figura 4). O próprio parque resultante do projeto de Niemeyer, com seus pavilhões, era enaltecido em manchete de 22 de maio de 1952: "Da grande área do Ibirapuera surgirá um 


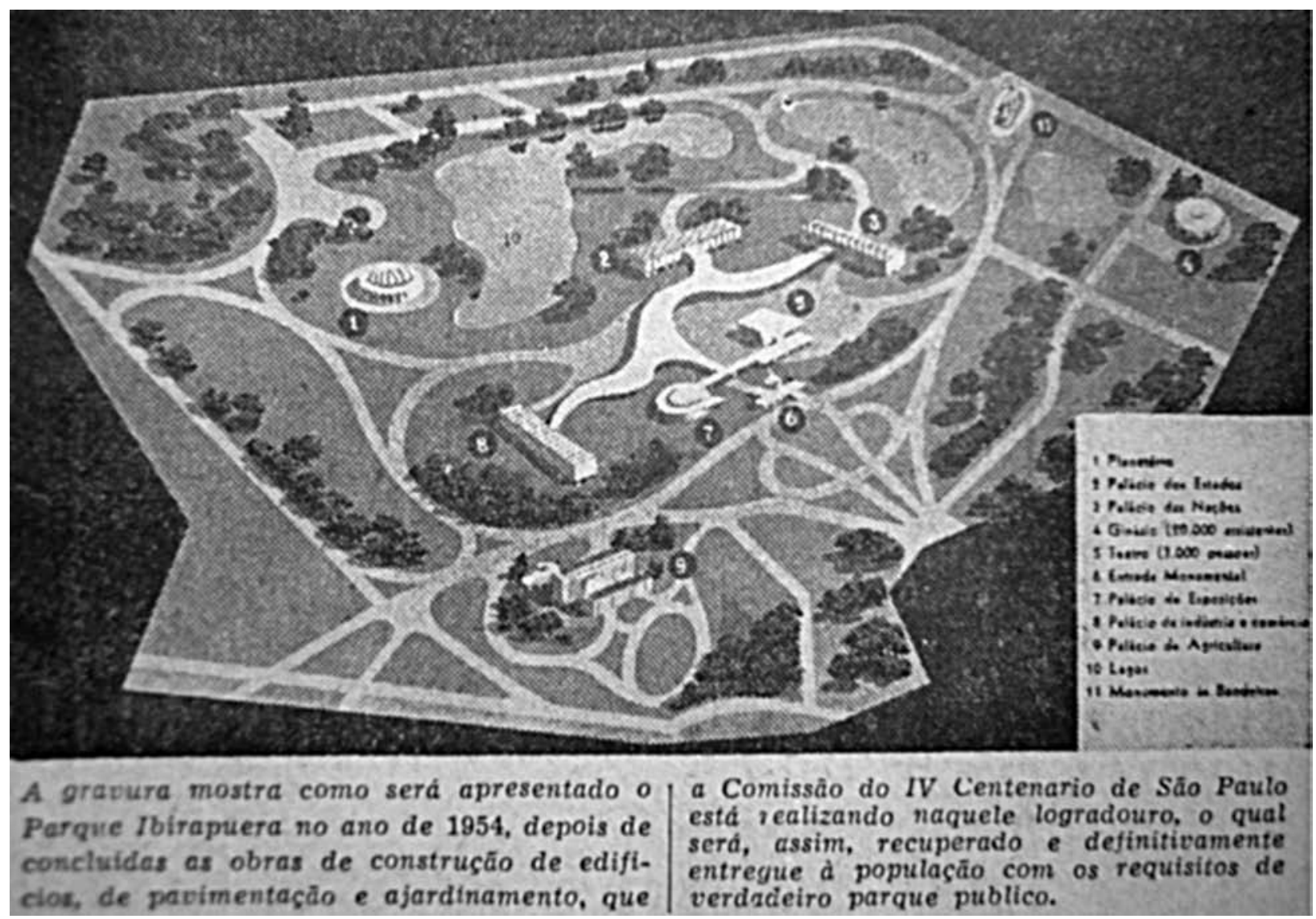

Figura 4 - Maquete do parque publicada com destaque pelo Diário de São Paulo, na primeira página da edição de 24 de janeiro de 1953.

verdadeiro parque"64. A notícia frisava que havia tempo suficiente para a execução do parque, acalmando os ânimos exaltados contra os trabalhos da Comissão. Especificamente sobre os pavilhões, o jornal noticiava com entusiasmo que "serão entregues até o fim do ano os pavilhões do lbirapuera"65.

Reiterando a ideia da reincidência e multiplicação da representatividade de um único grupo, tudo leva a crer que o colunista de Anhembi era o próprio editor da revista, Paulo Duarte. Outro pesquisadorbo já atribuíra a Duarte a autoria do artigo. Além de dirigir Anhembi, Duarte era redator de $\bigcirc$ Estado de São Paulo desde 1927. $\bigcirc$ jornalista era um forte oponente da ideia de pavilhões de exposições tomarem lugar no Parque Ibirapuera, considerando os festejos como a destruição de um dos raros cinturões verdes da cidade. Em 1949, publicou naquele jornal uma longa defesa do parque exclusivamente verde, lembrando os feitos de Fábio Prado para assegurar sua implantação ${ }^{67}$. Além desse, assinou diversos outros artigos sobre a preservação do parque, usando um vocabulário e expressões bastante semelhantes às do artigo anônimo. Compare-se, por exemplo, os trechos citados de Anhembi com o seguinte artigo de Duarte no Estado:
64. Diário de São Paulo, 22 maio 1952.

65. Idem, 20 mar. 1953

66. Ver J. Toledo (1994)

67. Ver OESP, 8-9 set. 1949

Annals of Museu Paulista. v. 17. n.2. July - Dec. 2009. 
68. Idem, p. 8, 23 jul 1952.

69. Ibidem.
O que há de lamentável na mutilação de um parque público entra pelos olhos de todos e evidentemente já entrou também pelos olhos dos poderes públicos que não tomaram conhecimento do que está acontecendo [...]. Agora localizou-se nele, contra tudo e contra todos, a exposição de 1954. O pior é que, segundo corre, estão sendo executadas no local não apenas obras provisórias, mas edificações definitivas, quer dizer, a condenação irremissível do Parque Ibirapuera [...] Vê-se, pois, que a teimosia com que se persiste em localizar uma exposição no Ibirapuera é fruto mais de um capricho do que qualquer outra orientação [...] Assim, não era possivel que naquela Comissão Cultural das comemorações não se levantasse um protesto contra esse gesto profundamente prejudicial à cidade, antipático e revoltante mesmo ${ }^{68}$.

Em suas memórias, Duarte reforçava tal perspectiva ao destacar os esforços do prefeito Fábio Prado, entre 1934 e 1938, para viabilizar a implantação do parque:

Já em 1937 prosseguiam ativíssimos os trabalhos de ajardinamento e organização do Parque de Ibirapuera, entregues então à competência inigualável de Manequinho Lopes. No início de 1938, deixava a Prefeitura o sr. Fábio Prado e o lbirapuera foi abandonado. Durante oito anos de administração do sr. Prestes Maia, parece incrível tratando-se de um prefeito para o qual administração municipal era apenas urbanismo, mas durante anos de administração do sr. Prestes Maia, o lbirapuera ficou abandonado! Não era de admirar pois que os que seguiram nada fizessem. E o lbirapuera que fora já vitima de inúmeras invasões, uma parte cedida a um quartel, uma grande parte cedida ao Instituto Biológico, uma parte tomada pelos grileiros, contra os quais a prefeitura se mostrou incapaz de defender-se, passou por outra série de vicissitudes que se renovaram todos os dias. A administração Fábio Prado defendera aquela área contra a ideia primeiro de instalar-se ali o Jóquei Clube e, a seguir, o aeroporto, que foi depois localizado em Congonhas ${ }^{69}$.

Ou seja, a coincidência entre as argumentações nos diversos meios institucionais e de comunicação deve-se também à atuação de Paulo Duarte em vários deles.

Dessa forma, supõe-se que, se houve outros grupos de oposição ao projeto do Parque Ibirapuera, esses foram parcamente representados nas fontes de documentação consultadas. A coincidente filiação política entre Anhembi e o Estado, ambos alinhados às posições do Partido Democrático de Armando Salles de Oliveira, levam a vislumbrar uma vinculação partidária do tema da defesa do verde e da natureza no parque naquele momento.

\section{Mudança de perspectiva}

Finalmente, é preciso ainda dizer que, depois de toda a celeuma em torno da defesa do parque contra os pavilhões, Duarte e o Estado acabaram por defender veementemente os edifícios, agora contra sua ocupação por órgãos administrativos e em prol da instalação de instituições culturais em suas dependências. 
Desde o final das comemorações do IV Centenário, a autarquia da Comissão transformou-se em Fundação Ibirapuera, com Ciccillo na presidência. A proposta, encampada pela Fundação, desta feita altamente defendida pelo Estado, era de transformar-se o parque em um centro cultural, especificamente no setor compreendido pelo conjunto de pavilhões. Porém, o projeto estava impedido em função do plano municipal do então prefeito Jânio Quadros de instalar dependências administrativas no local. Diversos artigos foram publicados no jornal entre 1955 e 1957, reprovando essa decisão. Os mesmos termos, "mutilação" e "desvirtuamento" eram usados, agora, para designar a nova destinação dos edifícios.

próprio Duarte, em homenagem a Ciccillo, anos depois, defendeu a ideia dos pavilhões, com a finalidade de instalar entidades culturais no parque:

Depois dos festejos comemorativos, queria fazer do lbirapuera o maior centro de cultura e lazer do país. Os palácios ali construídos, após servirem aos festejos, deveriam tornar-se casas de cultura, como era seu desejo. Mas foram ocupados por outras atividades completamente fora do assunto cultural, intelectual e espiritual. $\bigcirc$ prédio que se destinava ao Museu de Arqueologia de São Paulo foi ocupado pelo Estado, instalando ali a repartição de trânsito, o DETRAN. Um outro que deveria ser também museu abriga uma repartição pública que, de tão importante que é, até não me lembro do nome. Outro dos pavilhões que deveria ser aproveitado para a vida espiritual e intelectual é hoje sede da Prefeitura ${ }^{70}$.

A perplexidade diante da mudança de posição de Paulo Duarte e demais críticos ao projeto do parque adquire um novo contorno se pensada como elemento explicativo para o posterior silêncio sobre o antagonismo aos pavilhões. Por que, logo em seguida, aquela pluralidade de vozes anunciada pelo colunista de Anhembi calou-se tão completamente? Talvez porque a oposição não fizesse mais sentido após a implantação do parque. Se é correto que não eram múltiplas vozes, mas uma única voz amplificada e multiplicada em diversos meios de representação, essa voz lutava antes por se fazer presente nas instâncias de decisão que propriamente pela defesa de um ou de outro projeto. $\bigcirc$ parque exclusivamente verde era seu mote, indicando uma matriz politicamente identificada do pensamento urbanístico paulistano no período, alinhada com as posições do Partido Democrático. Ao serem convidados a participar da Comissão, os opositores se fizeram representar e mudaram de posição, passando inclusive a lutar para levantar recursos para o financiamento de uma das edificações a serem instaladas no parque. Ao mesmo tempo, passou a ser mais importante defender o programa cultural nos pavilhões contra a implantação de alguns órgãos da burocracia do Estado.

Cabe esboçar, assim, uma possível interpretação para o problema levantado: o programa cultural então ameaçado era crucial para o grupo de ex-oponentes. $\bigcirc$ projeto dos pavilhões era agora parte desse programa cultural. $\bigcirc$ parque exclusivamente verde dava lugar ao parque que aliava o contato com a natureza ao desenvolvimento da cultura. Há aqui opções políticas claramente
70. Ver Paulo Duarte, Homem generoso, inclinado às aspirações culturais, 4 mai. 1976, Arquivo Histórico Wanda Svevo, fundo Francisco Matarazzo Sobrinho, pasta n. 411. 
delineadas no sentido da definição de "para quem" o novo parque estava sendo construído, com sua natureza preservada, suas feiras de exposições, sua oferta cultural, mas o tema requer um debate mais aprofundado dos pressupostos políticos desses projetos, que foge ao escopo deste pequeno artigo. Por ora, vale mais a pena perceber que o sucesso das comemorações do IV Centenário, o projeto moderno de Niemeyer e as Bienais de Arte eram de tal forma coincidentes com as prerrogativas dos oponentes que ficava difícil manterem o antagonismo ao projeto do parque - desde que o grupo estivesse suficientemente representado em tal investida, desde que pudesse estar identificado entre os seus propositores. Superados os entraves de representação de poder, era irresistivel comemorar a pujança econômica de São Paulo por meio de sua soberania cultural. Tornou-se um uníssono. A partir do êxito da empreitada de 1954, era mais relevante apagar os vestígios dos conflitos e exaltar a modernidade da cidade em todos campos, agora com um parque dotado de um complexo que unia natureza, lazer e cultura na maior e mais poderosa cidade do pais.

\section{REFERÊNCIAS}

\section{MANUSCRITOS}

CARTA à Comissão do IV Centenário, 13 set. 1951, Arquivo Histórico Municipal Washington Luis, fundo IV Centenário, série Gabinete, processo 215.

DUARTE, Paulo. Homem generoso, inclinado às aspirações culturais [discurso de homenagem a Ciccillo Matarazzo, proferido em 4 mai. 1976]. Arquivo Histórico Wanda Svevo da Fundação Bienal de São Paulo, fundo Francisco Matarazzo Sobrinho, pasta n. 411.

OFíCIO de 26 jun. 1951, Arquivo Histórico Municipal Washington Luis, fundo IV Centenário, caixa 85 , processo 173 .

SOCIEDADE AMIGOS DA CIDADE. Livro de atas, 06 fev 1935 a 19 mai 1937.

Livro de atas, 17 set 1951 a 14 set 1955.

\section{ARTIGOS EM PERIÓDICOS}

AINDA o Ibirapuera. O Estado de São Paulo, São Paulo, Notícias Diversas, p. 13, 11 maio 1952.

CÂMARA Municipal: aproveitamento do Parque Ibirapuera. O Estado de São Paulo, São Paulo, p. 4, 10 abr.1951.

COMISSÃO do IV Centenário. O Estado de São Paulo, São Paulo, p. 10, 3 set. 1952; e p. 13 , 16 set. 1952.

CONTRA a destruição do Parque Ibirapuera. O Estado de São Paulo, São Paulo, Notícias Diversas, p. 9,19 set. 1951 .

CONTRA o Ibirapuera. O Estado de São Paulo, São Paulo, p. 13, 9 mar. 1952. 
Diário de São Paulo, São Paulo, 20 mar. 1953.

Diário de São Paulo, São Paulo, 22 maio 1952.

DUARTE, Paulo. Ibirapuera. O Estado de São Paulo, São Paulo, 8-9 set. 1949.

MACHADO, Lourival Gomes. A propósito da II Bienal, nem todo número é ouro. O Estado de São Paulo, São Paulo, 15 dez 1953.

MUTILAÇÃO do Parque Ibirapuera. Anbembi, São Paulo, v. 10, n. 29, abr. 1953.

O DESVIRTUAMENTO do Ibirapuera. O Estado de São Paulo, São Paulo, p. 5, 3 jul. 1952.

O IV CENTENÁRIO da cidade. A mutilação do Ibirapuera. O Estado de São Paulo, São Paulo, p. 8,23 jul. 1952.

O Estado de São Paulo, São Paulo, p. 9,19 jul. 1952.

OS ABANDONADOS jardins, parques e praças públicas do Brasil. Anbembi, São Paulo, v. 5, n. 13, p. 130-136, dez. 1951.

PARQUES e Jardins de S. Paulo, I. O Estado de São Paulo, São Paulo, p. 9, 3 jul. 1951.

PARQUES e Jardins de S. Paulo, II. O Estado de São Paulo, São Paulo, p. 9, 8 jul. 1951.

PARQUES e Jardins de S. Paulo, III. O Estado de São Paulo, São Paulo, p. 7, 11 de jul. 1951.

PARQUES e Jardins de S. Paulo, IV. O Estado de São Paulo, São Paulo, p. 9, 15 jul. 1951.

PARQUES e Jardins de S. Paulo, V. O Estado de São Paulo, São Paulo, p. 8, 18 jul. 1951.

SUGESTÕES para o IV Centenário. O Estado de São Paulo, São Paulo, Notícias Diversas, p. 8, 20 mar. 1952.

OBRAS GERAIS

ARRUDA, Maria Arminda do Nascimento. Metrópole e cultura. São Paulo no meio do século XX. Bauru: Edusp, 2001.

BARONE, Ana Cláudia Castilho. Ibirapuera: parque metropolitano (1926-1954). 2007. Tese (Doutorado em Urbanismo) - Faculdade de Arquitetura e Urbanismo da Universidade de São Paulo, São Paulo, 2007.

DUARTE, Paulo. Memórias III. Selva obscura. São Paulo: Hucitec, 1976.

Memórias IV. Os mortos de Seabrook. São Paulo: Hucitec, 1976.

INSTITUTO CULTURAL ITAÚ. Cadernos da cidade de São Paulo: parque do Ibirapuera. São Paulo: ICI, 1997.

MARIANO, Cássia Regina. Preservação e paisagismo em Otávio Augusto Teixeira Mendes. 2003. Tese (Doutorado em Urbanismo) - Faculdade de Arquitetura e Urbanismo da Universidade de São Paulo, São Paulo, 2003.

MARINS, Paulo César Garcez. O Parque Ibirapuera e a construção da identidade paulista. Anais do Museu Paulista, história e cultura material, São Paulo, v. 6-7, p. 9-36, 1998-1999. 
MEYER, Regina Maria Prosperi. Metrópole e urbanismo: São Paulo anos 50. 1991. Tese (Doutorado em Urbanismo) - Faculdade de Arquitetura e Urbanismo da Universidade de São Paulo, São Paulo, 1991.

OLIVEIRA, Fabiano Lemes. Os projetos para o Parque Ibirapuera: de Manequinho Lopes a Niemeyer (1926-1954). 2003. Dissertação (Mestrado em Arquitetura) - Escola de Engenharia de São Carlos da Universidade de São Paulo, São Carlos, 2003.

SAMPAIO, Maria Ruth Amaral de (Org.). São Paulo 1934-1938: anos da administração Fábio Prado. São Paulo: Faculdade de Arquitetura e Urbanismo da Universidade de São Paulo, 1999.

TELlES, Goffredo T. da Silva. São Paulo. Cidade sem parques e sem áreas livres. Edições da Sociedade Amigos da Cidade, São Paulo, n. 8, mai. 1950.

TOLEDO, J. Flávio de Carvalbo, o comedor de emoções. Campinas: Editora da Unicamp; São Paulo: Brasiliense, 1994.

Artigo apresentado em 5/2009. Aprovado em 9/2009. 